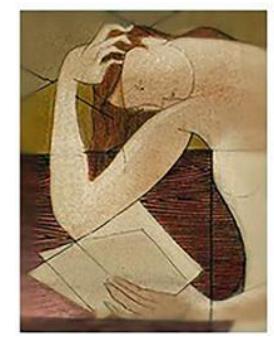

\title{
As narrativas implícitas e explícitas nos contos de Machado de Assis: uma análise comparativa das formas de produção literária
}

\section{The implicit and explicit narratives in Machado de Assis tales: a comparative analysis of the forms of literary production}

\author{
Brunna Luiza Lima de Sousa ${ }^{1}$
}

\begin{abstract}
Resumo: Este trabalho tem como objetivo analisar quatro contos do escritor brasileiro Machado de Assis: Um Homem Célebre (1896); Cantiga dos Esponsais (1884); O Machete (1878) e Virginius (1864). Com o intuito de enxergar como se configuram em seus textos as narrativas implícitas e explícitas - partindo do entendimento de que tais narrativas são formas de construções textuais que possibilitam contar uma história que pode conter camadas de aprofundamentos nas ações dos personagens, narração ou na descrição de cenas -, a justificativa da escolha dos respectivos contos é por acreditar que o autor levantou questões implícitas que podem ser analisadas do ponto de vista da escrita criativa. Para tanto, busca-se entender as seguintes questões: o que é um enredo explícito e implícito? Como ele se configura e se desenvolve dentro de uma obra? Quais são os fatores (externos e internos) e técnicas que possibilitam a identificação dessa diferença? E por que ela é importante dentro do um contexto de produção e de leitura literária?
\end{abstract}

Palavras chaves: Machado de Assis; escrita criativa; narrativa; implícito; explícito.

Abstract: This work aims to analyze four short stories by the Brazilian writer Machado de Assis: $A$ Famous Man (1896); Song of the Spousal (1884); The Machete (1878) and Virginius (1864). In order to see how implicit and explicit narratives are configured in their texts — based on the understanding that such narratives are forms of textual constructions that make it possible to tell a story that may contain layers of depths that are not necessarily explicit in the actions of the characters, narration or in the description of scenes —, the justification for the choice of the respective stories is for believing that the author raised implicit questions that can be analyzed from the point of view of creative writing. Therefore, we seek to understand the following questions: what is an explicit and implicit plot? How is it configured and developed within a work? What are the factors (external and internal) and techniques that make it possible to identify this difference? And why is it important within the context of literary production and reading?

Keywords: Machado de Assis; creative writing; narrative; implicit; explicit.

\section{O que é um enredo explícito e implícito?}

Toda história tem uma estrutura de leitura. Quando assistimos a uma peça de teatro, temos uma estrutura de leitura coletiva, ou seja, assistimos ao lado de outras pessoas. A peça de teatro geralmente tem o objetivo de contar uma história com foco nas ações e diálogos dos personagens, com pouco tempo e recursos para transportar o

\footnotetext{
${ }^{1}$ Bacharel em Comunicação Social pela Universidade de Brasília. Mestranda em Letras na Universidade Federal do Rio Grande do Sul.
} 
espectador para um aprofundamento maior da história. Quando assistimos a um filme (no cinema ou em casa), podemos ou não manter a estrutura da leitura coletiva. Mas, diferente do teatro, no cinema contamos com mais recursos técnicos, como a construção de planos e cenas através da filmagem, que possibilitam uma nova forma de apresentar a história.

Já a estrutura da literatura não tem tantos recursos técnicos, pois o leitor precisa imaginar as cenas que saem dos textos. Não estão explícitas para o leitor as ações, imagens e sons, como no filme e no teatro. O leitor abre um livro e precisa imaginar, através dos significados, o que está sendo mostrado. Além disso, dificilmente conseguimos ler um livro com outra pessoa. A leitura é individual e, por isso, cada pessoa forma sua imagem e a interpretação daquele texto.

O escritor e professor de escrita criativa americano Robert McKee, em seu livro Diálogo - a arte da ação verbal na página, no palco e na tela (2018), aborda a diferença existente entre os três tipos de narrativas:

A prosa é um meio mental. Enquanto estórias executadas no palco ou na tela miram direto nos olhos e nas orelhas do público, a literatura percorre um caminho indireto pela mente dos leitores. O leitor deve primeiro interpretar a linguagem e depois imaginar os sons e imagens descritos (cada leitor imagina do seu jeito) para só então, reagir ao que foi imaginado. (MCKEE, 2018, p. 27)

Seguindo esse raciocínio, assim como existem narrativas com diferentes estruturas de leitura, cada uma com seu respectivo recurso técnico (teatro, cinema, livro, oralidade), existem também maneiras diferentes de se estruturar um texto. A maneira de se estruturar um texto pode ser definida como o tipo de voz narrativa, o gênero, o tipo de diálogo (quando há diálogo), o grau de detalhamento que o escritor dá para a cena e a abertura que ele deixa para o leitor. A ideia de narrativa implícita nesse sentido é de uma narrativa que não explique tudo para o leitor, e sim faça-o interpretar acontecimentos que não são explícitos. Assim como na literatura, em comparação com o teatro e cinema, temos de fazer um esforço para imaginar as cenas, na narrativa implícita o escritor pode criar histórias que exijam mais atenção do leitor. Ou melhor, uma dupla atenção, já que a literatura por si só exige uma maior capacidade de imaginação.

Sendo assim, os enredos implícitos e explícitos podem ser conceituados como formas de se estruturar uma história: quanto menos recursos o leitor tem para visualizar as imagens ali escritas, mais a história depende da sua interpretação, atenção e bagagem cultural. 


\section{A escrita implícita e explícita na literatura}

Umberto Eco, em suas teorias sobre autor e leitor modelo no livro Seis passeios pelos bosques da ficção (1994), já afirmava que o leitor é fundamental no processo de contar uma história. Para ele, o texto é uma máquina preguiçosa pedindo ao leitor que faça uma parte de seu trabalho. Eco escreve:

\footnotetext{
Por enquanto, só quero dizer que qualquer narrativa de ficção é necessária e fatalmente rápida porque, ao construir um mundo que inclui uma multiplicidade de acontecimentos e de personagens, não pode dizer tudo sobre esse mundo. Alude a ele e pede ao leitor que preencha toda uma série de lacunas. (ECO, 1994, p. 9)
}

Ou seja, Eco defende a importância do leitor, porque na narrativa escrita existem poucos recursos para transportar o leitor para aquele mundo. É importante que o leitor seja um Leitor Modelo: um leitor ideal que o texto não só prevê como colaborador, mas ainda procura criar; o qual deve ser pelo menos uma pessoa disposta a aceitar algo que extrapole o sensato e o razoável (ECO, 1994).

$\mathrm{Na}$ literatura, existem histórias que lemos com muita rapidez, pois as imagens que vemos através das palavras estão repletas de ações de personagens e diálogos que vão direto ao ponto. Podemos identificar qual é o conflito com facilidade e as situações que acontecem no enredo nos aparecem sem fazermos muito esforço; enquanto existem histórias que não dão as informações de forma explícita, que tendem a serem menos detalhadas, com uma ou mais camadas de interpretação e construção de personagens mais aprofundados que levam o leitor a outra complexidade de leitura. Como Umberto Eco afirmou, o leitor precisa preencher algumas lacunas para entender a história. Podemos inferir, então, que as narrativas implícitas são histórias escritas pelo escritor que precisam da ajuda do leitor para reconhecer suas devidas camadas e significados.

Ricardo Piglia, escritor argentino, já escrevia em Teses sobre o conto, publicado no livro Formas Breves (2004), que um conto sempre tem duas histórias. A primeira é a que temos acesso, e a segunda história é a narrativa mais profunda que subjaz à primeira; quanto mais abertura um texto tem, maior a quantidade de possibilidades para a segunda história. Para ele, um conto é um relato que encerra um relato secreto, e o conto segredo é a chave da forma do conto e suas variantes. Segundo Piglia,

A arte de narrar é a arte da percepção errada e da distorção. O relato avança segundo um plano férreo e incompreensível, e perto do final surge no horizonte a visão de uma realidade desconhecida: o final faz ver um sentido secreto que estava cifrado e como que ausente na sucessão clara dos fatos. (PIGLIA, 2004, p. 103) 
Piglia escreveu que uma história pode ser contada de maneiras distintas, mas que sempre há um duplo movimento, algo incompreensível que acontece e está oculto. E cabe ao leitor descobrir o relato oculto dessas histórias. Segundo essa teoria, se todo conto pode ter duas histórias, então um romance, ou uma poesia ou qualquer produção ficcional literária, também pode ter duas histórias. Na teoria de Piglia, a primeira história pode ser entendida como a narrativa explícita e a história oculta como a narrativa implícita. E aqui cabe ao autor entender essas técnicas e utilizá-las em suas produções ficcionais.

Em resumo, a importância de saber que existe, dentro da literatura, histórias que são explícitas e implícitas é entender como o leitor se desenvolve a partir dessas leituras. Quem é capaz de ler histórias implícitas? Somente leitores mais experientes ou crianças e adolescentes também são aptos a lerem este tipo de enredo? E o escritor, no momento em que escreve, tem consciência sobre a técnica desse tipo de enredo? O objetivo desse artigo, ao analisar os contos propostos, é entender o que são essas narrativas e como elas podem influenciar no desenvolvimento da leitura e da produção literária. Tanto para formar leitores com maior capacidade de interpretação, quanto escritores capazes de desenvolver histórias com diferentes níveis de complexidade.

\section{Os contos de Machado de Assis}

Machado de Assis foi um escritor negro brasileiro considerado um dos maiores nomes da literatura brasileira. Nascido em 21 de junho de 1839 e falecido em 29 de setembro de 1908, Machado viveu no período escravocrata e vivenciou a abolição da escravidão no Brasil. Escreveu inúmeros contos e romances, sendo sua produção literária bastante referenciada até hoje. Muitos de seus contos abordam as questões sociais e políticas da época, ainda que existam dúvidas sobre o quanto de intencionalidade de cunho social Machado colocou em suas histórias. Nos contos que iremos analisar neste trabalho, veremos se é possível identificar duas camadas de histórias: uma explícita e outra implícita.

Para essa análise foram selecionados quatro contos de Machado: Um Homem Célebre (1896); Cantiga dos Esponsais (1884); O Machete (1878) e Virginius (1864). Todos os contos foram escritos no século XIX e os três primeiros têm em comum a figura do artista músico e compositor da época. Os personagens dos três primeiros contos são músicos fracassados que se sentem inconformados com a sua arte e o seu 
trabalho, não conseguem produzir da forma como queriam e nem ter o sucesso ou o reconhecimento que desejam.

Pestana, personagem do conto Um Homem Célebre, é um músico com certo reconhecimento, pois produz polcas, um gênero musical europeu mais dançante que muitas pessoas apreciavam na época, apesar de não ser o seu estilo musical favorito. $\mathrm{O}$ que Pestana gostaria mesmo era de escrever músicas clássicas, assim como seus ídolos Cimarosa, Mozart e Beethoven. No entanto, ele não consegue ter inspiração o suficiente para isso e sente-se muito infeliz. O trecho a seguir retrata o sentimento do personagem:

Às vezes, como que ia surgir das profundezas do inconsciente uma aurora de ideia: ele corria ao piano para aventá-la inteira, traduzi-la, em sons, mas era em vão: a idéia esvaía-se. Outras vezes, sentado, ao piano, deixava os dedos correrem, à ventura, a ver se as fantasias brotavam deles, como dos de Mozart: mas nada, nada, a inspiração não vinha, a imaginação deixava-se estar dormindo. (ASSIS, Um Homem Célebre, p. 3).

No conto Cantiga dos Esponsais, Mestre Romão é um músico que rege missas com alma e devoção, muito famoso e conhecido na região pelo seu talento. A sua maior angústia é a de não conseguir compor. Apesar de amar a música, não tem inspiração nenhuma para compor uma letra. No final do conto, o autor nos mostra Romão cheio de tristeza por não alcançar o seu tão sonhado objetivo. Machado nos deixa claro logo no início do conto o grande conflito do personagem:

Ah! se mestre Romão pudesse seria um grande compositor. [...] Tinha a vocação íntima da música; trazia dentro de si muitas óperas e missas, um mundo de harmonias novas e originais, que não alcançava exprimir e pôr no papel. (ASSIS, Cantiga dos esponsais, p. 2).

Inácio, do conto $O$ Machete, é um violoncelista que, diferentemente dos dois personagens anteriores, não é angustiado com trajetória musical. Pelo contrário, é feliz com a sua arte e, muitas vezes, prefere não mostrar para as outras pessoas as suas composições. Porém, a trama principal do conto acontece quando aparece outro personagem, Barbosa, que se interessa em tocar um outro instrumento: o machete. Barbosa acaba conquistando todos ao redor de Inácio, inclusive a sua esposa, com a música advinda do machete. Isso enlouquece Inácio que sempre acreditou que a sua música e seu violoncelo eram melhores até se ver sem esposa e sem amigos. Ao final do conto, ele está triste e melancólico:

[...] — Mas que há? articulou o estudante. — Oh! nada, disse Inácio, ela foi-se embora, foi-se com o machete. Não quis o violoncelo, que é grave demais. Tem razão; machete é melhor.

A alma do marido chorava, mas os olhos estavam secos. Uma hora depois enlouqueceu. (ASSIS, O Machete, p. 10). 
O conto Virginius tem uma temática diferente dos contos anteriores. Nele é retratado a trajetória de um advogado que um dia recebe uma carta de um desconhecido, pedindo que o ajudasse em um julgamento de um amigo em uma cidade próxima. Ele vai para essa cidade e, antes de falar com o autor da carta, encontra um antigo amigo que logo lhe revela que a letra da carta é de um homem muito poderoso na cidade. $\mathrm{O}$ homem, que se chama Pio, é dono de terras e conhecido por ser o Pai de Todos considerado assim, inclusive pelos escravos, pela sua benevolência. O julgamento, por sua vez, é de um dos escravos de Pio, chamado Julião. Julião está sendo julgado pelo assassinato de sua filha Elisa, que é morta por ele antes que ela sofresse um estupro do filho de Pio. O argumento de Julião é de que estaria salvando a filha, pois a morte, diante da alternativa, é mais favorável do que a desonra de ser violentada. Julião é preso por assassinato, porém Pio, o Pai de Todos, se comove com os acontecimentos e, ao sentir-se responsável pelo sofrimento de seu antigo escravo, contrata um advogado, o narrador do conto, para ajudar Julião a diminuir sua pena.

Nos três primeiros contos, a voz narrativa predominante é a de terceira pessoa. Trata-se de um narrador oculto. Além disso, Machado utiliza muitos diálogos e ação dos personagens. Não é uma estrutura digressiva, mas sim descritiva e narrativa, em que Machado mostra mais a ação dos personagens. No entanto, conseguimos acessar os sentimentos dos músicos e a sua frustração. Ao lembrarmos a teoria de Ricardo Piglia, essa história da trajetória dos músicos é a que temos acesso. Por que eles são tão frustrados e por que não atingem o sucesso que desejam? Por que o personagem Pestana, mesmo tendo sucesso com suas polcas, não é feliz? Por que sua vida acaba de forma tão frustrante? Por que Mestre Romão passa a vida inteira sem conseguir compor uma música sequer? Por que essa é a maior tristeza de sua vida? Por que Inácio acaba enlouquecendo? Qual a relação desses personagens com seu contexto? É a falta dessas explicações que pode levar o leitor à história oculta. Identificando a história oculta é que conseguimos identificar as duas histórias do conto: a implícita e a explícita.

No conto Virginius, a temática é diferente. Nesse caso, é abordada a situação de um ex-escravo e o seu crime hediondo contra a filha. A construção do personagem e seus argumentos são muito bem elaborados. Neste conto, Machado utilizou a narração em primeira pessoa: o narrador é um personagem que não está dentro do conflito principal, ele é um advogado que foi defender o personagem principal, o Julião exescravo. A sua narração também não tem caráter digressivo, e os diálogos nesse conto 
não se destacam em comparação com os outros contos. Machado utiliza mais da narração e do tempo passado para narrar os acontecimentos. O narrador está no tempo presente, mas o que ele narra está no tempo passado, pois ele está contando para o leitor a história principal a partir da sua visão. Assim como no conto dos músicos, a história explícita é a que conseguimos acessar, ou seja, o crime do ex-escravo e a diminuição da sua sentença. Mas a história implícita é a que o leitor precisa descobrir a partir dos acontecimentos que existem na história explícita.

\section{As narrativas implícitas nos contos de Machado de Assis}

A partir dos resumos apresentados tentaremos encontrar as narrativas implícitas dos contos de Machado de Assis, partindo do entendimento de que existem dois tipos de histórias na literatura. A primeira pode ser definida como a história principal, a qual o leitor consegue acessar e desvendar, pois não existem camadas implícitas. A história tem início, meio, fim, e todos os fatos e enigmas são desvendados e contados pelo próprio narrador, sendo o leitor apenas um espectador.

A segunda narrativa pode ser definida como aquela história que tem mais do que uma camada. Normalmente, essas narrativas utilizam o artifício de múltiplas camadas para abordar assuntos complexos de maneiras simples para surpreender o leitor. Ou ainda, para abordar determinados assuntos que não podem ser ditos por motivos de censura ou falta de aceitação social. Esse tipo de narrativa, presente na maioria da produção literária que hoje conhecemos, depende da sensibilidade, atenção e bagagem cultural do espectador ou leitor. Sem isso, o leitor pode apenas acessar a primeira camada e acreditar que foi a única que o escritor escreveu, sem conseguir acessar a segunda história por trás.

Nos contos Um Homem Célebre, Cantiga dos esponsais e $O$ Machete, a primeira camada vem das histórias dos músicos já citadas: a construção do personagem, seu conflito, seus desejos, suas frustrações e o seu fim trágico. Já a camada que não está clara de imediato é que é possível considerar, a partir do contexto social da época, que os personagens principais seriam negros em condição de homens livres.

Durante o século XIX, os artistas ocupavam uma posição social entre as classes médias e baixas da hierarquia social. Naquela época, poucos prosperavam chegando à classe média. Desse modo, podemos considerar a atividade de músico como uma ocupação relacionada apenas à sobrevivência e não como um caminho para a obtenção de um reconhecimento social e realização individual. Os artistas, ainda que de modo 
distinto, vivem à margem da sociedade: são sujeitos pobres ou que sobrevivem com dificuldades.

$\mathrm{O}$ artigo Músicos negros no Brasil colonial: trajetórias individuais e ascensão social (segunda metade do século XVIII e início do XIX), publicado na revista Vernáculo em 2007, escrito por Fernando Prestes de Souza e Priscila Lima, aborda as estratégias e possibilidades mobilizadas por homens negros livres a fim de ascenderem socialmente, conforme os padrões do antigo regime, tendo como esteio o ofício e a arte musical. Os autores explicam que, com a chegada da família real portuguesa no Rio de Janeiro em 1808, houve a implantação da cultura europeia no Brasil na arte e na música com a intenção de inserir mudanças para maior execução de música erudita e clássica.

Nesse processo, grande parte da população de negros livres se inseriu nesse ofício. Assim, ao entendermos que existia uma camada intermediária formada por homens negros livres que ocupavam cargos de músicos e artistas, podemos identificar os personagens dos contos de Machado como pertencentes desse grupo.

Nas palavras dos autores:

De fato, muitos foram os viajantes europeus que deixaram registradas suas impressões sobre a arte da música na nova corte de D. João VI. Um deles foi o cientista francês Louis Claude Desaulces Freycinet (1779-1842), que esteve no Rio de Janeiro entre 1817 e 1818, segundo o qual a música executada na Capela Real era admirável e "constituída quase que inteiramente de artistas negros, e cuja execução não deixa nada a desejar". Desta passagem chamamos a atenção para o fato de que os músicos que compunham a Real Capela eram majoritariamente negros. (LIMA; SOUZA, 2007, p. 30)

O fato de a classe de músicos ser constituída majoritariamente por negros no século XIX apresenta inúmeras interpretações para os contos que o Machado de Assis nos apresentou. Apesar de livres, esses homens eram negros e inseridos em um contexto marcado pela escravidão. Logo, podemos inferir que viviam em uma sociedade racista e preconceituosa, pois o fato de serem livres não significa que eram imunes ao preconceito racial decorrente da cor de suas peles. Apesar desse tema não ser abordado nos contos, sabemos que a vida desses homens era marcada pelas estruturas racistas da sociedade brasileira.

Em meados do século XVI até o século XIX, aproximadamente 12,5 milhões de africanos escravizados foram trazidos à força para as Américas. O tráfico de escravos para o Brasil tem sido caracterizado por muitos estudiosos e movimentos negros como uma experiência desumanizante para a população africana. Milhares de negros migraram para o Brasil e foram submetidos a uma série de violências físicas e mentais. 
Nesse contexto, muitos escravos cometiam suicídio como uma forma de se livrar das atrocidades e violências sofridas na condição de cativos.

A obra Dicionário da Escravidão Negra no Brasil, escrito por Clóvis Moura e Soraya Silva Moura em 2004, traz um conceito chamado Banzo, um termo que ficou conhecido como um estado mental caracterizado principalmente por uma tristeza muito profunda que acometia os escravos assim que eles desembarcavam dos navios negreiros no território brasileiro. Moura define Banzo como:

Estado de depressão psicológica que se apossava do africano logo após seu desembarque no Brasil. Geralmente os que caíam nesta nostalgia profunda, acabavam morrendo. Atribui-se tal estado depressivo à saudade da aldeia da qual provinham, de modo que o banzo atingia somente a primeira geração de escravos, isto é, aqueles diretamente importados da África. (MOURA, 2004, p. 63).

O Banzo é um exemplo das inúmeras doenças mentais que os negros adquiriram após anos e anos de violência. Além de doenças mentais, os sentimentos de fracasso, angústia e incompetência que acometiam os negros livres músicos nos contos de Machado também podem ser relacionados com a questão racial. Com isso, podemos imaginar as dificuldades que esses indivíduos passavam sendo artistas e negros naquela época.

Já o conto Virginius gira em torno de outra situação. A primeira camada é a história de um ex-escravo, Julião, que mata a sua filha Elisa para impedi-la de ser estuprada pelo filho de seu antigo senhor. A segunda camada da história, ou seja, a história oculta, pode ser entendida como os direitos humanos desse ex-escravo e de sua filha. Diferentemente de outros escritores negros de sua época, como Luis Gama ou José de Patrocínio, Machado de Assis não abordava a questão racial de forma explícita. No entanto, ao analisar os respectivos contos e levar em consideração o contexto social da época, talvez seja possível que Machado tenha escrito essas histórias para sensibilizar seus leitores - a maioria pessoas de elite e brancas -, os fazendo enxergar com empatia e compaixão as pessoas negras.

Ao escrever Virginius, Machado colocou em pauta algumas questões: naquela época a honra, ou seja, a virgindade de uma mulher, era sagrada. Logo, para Elisa, sofrer uma violência sexual era tão insuportável quanto a morte. Além disso, o fato de ser estuprada pelo filho de um senhor de terras significaria voltar a ser objeto ou propriedade de quem a escravizou, negando a liberdade que ela tinha adquirido como uma negra livre. Já Julião, ao ser punido pelo assassinato de sua filha (a julgar pelo caráter sentimental e honroso que teoricamente fora o seu crime) teria que ter tido uma 
pena menor. $\mathrm{O}$ contexto no qual o conto foi escrito trazia a pauta do exercício da justiça por crimes cometidos por escravos. Considerando que existiam muitos escravos livres, os seus crimes, julgamentos e seus direitos estavam começando a entrar em discussão nos movimentos abolicionistas, sendo que uma das principais questões era: como lidar com a liberdade tão estrita que os homens negros livres, ex-escravos ou escravos tinham? Como funcionaria a justiça para os negros? Qual espaço os advogados abolicionistas tinham naquela época em que não existia legislação que amparasse esse grupo?

Esses e outros questionamentos estão presentes no livro Os direitos dos escravos, de Elciene Azevedo, escrito em 2010, que tem o objetivo de compreender os processos que envolvem a luta abolicionista durante as últimas décadas do século XIX no Brasil. Rejane Trindade, acadêmica em História pela Universidade Federal de Mato Grosso, em seu artigo na revista Trilhas da História (2013) em relação ao livro de Azevedo, escreve:

A autora vai além de uma compreensão, por muito tempo cristalizada em nossa historiografia, sobretudo pela "Geração de 1930", a qual entendia que o escravo devido a constância dos maus tratos a que era submetido, se tornava alheio a sua própria vontade. Sob essa leitura eram então sujeitos amorfos que não resistiam à violência, quando não eram ainda interpretados como inertes à escravidão pela benevolência de seus senhores, necessitando de homens brancos e ilustrados, repletos de sentimentos humanitários capazes de tirar-lhes da escura escravidão. (TRINDADE, Trilhas da História, 2013)

O crime de Julião somente foi digno de ter sua pena diminuída porque ele tinha matado um parente, ou seja, outra pessoa negra. Se, por exemplo, ele tivesse matado o filho de Julião, um homem branco, ao invés de Elisa, a sua pena não seria a mesma, pois ninguém iria tolerar que um ex-escravo matasse uma pessoa branca pelo senso de superioridade de raça existente naquele contexto. Além disso, a história de Julião comove tanto por não ser somente um negro matando outro negro, mas sim um pai tomando uma atitude drástica para impedir que tirassem a honra da sua filha:

Dispenso os leitores da narração do que se passou no júri. O crime foi provado pelo depoimento das testemunhas; nem Julião o negou nunca. Mas apesar de tudo, da confissão e da prova testemunhal, auditório, jurados, juiz e promotor, todos tinham pregados no réu olhos de simpatia, admiração e compaixão. (ASSIS, Virginius, p. 14)

\section{Conclusão}

A partir das análises apresentadas, podemos concluir que existem narrativas implícitas e explícitas e que elas podem exercer papéis fundamentais, quase sociológico, dentro da literatura. Isso mostra que o papel de uma narrativa vai muito além de apenas 
contar uma história. $\mathrm{O}$ autor precisa se preocupar com o seu leitor, com a complexidade de seus personagens - se eles são consistentes e mostram força expressiva em suas ações - e o alcance que elas terão.

Como vimos na análise, Machado de Assis escreveu três contos sobre artistas músicos que não conseguiram realizar seus sonhos e muitas vezes fracassaram em seus objetivos. Apesar de não podermos afirmar com toda a certeza de que a intenção de Machado era abordar a questão racial, todos os estudos da época apontam que a condição de artistas e músicos negros era muito influenciada pelo preconceito. A literatura é um reflexo da sociedade. As narrativas implícitas, nesse contexto, pode ser uma forma de analisar e problematizar situações em uma organização social.

Além de Machado de Assis, outros inúmeros escritores modernos e contemporâneos utilizam esse recurso na literatura. Já no século XX, durante a ditadura militar no Brasil, tivemos casos de artistas e escritores que escreviam histórias implícitas para denunciar e combater a violência do regime através das histórias que escreviam, atentos aos riscos de terem suas publicações censuradas. Teresa Cárdenas, escritora cubana, ao escrever o livro infanto-juvenil Cartas Para a Minha Mãe (2010), aborda o preconceito racial e o abuso infantil através de vivências simples de uma criança. Seu papel é fundamental para educar os leitores jovens acerca de situações que uma criança pode passar.

A literatura, o cinema e o teatro têm papéis educativos em uma sociedade. Muito mais do que apenas entreter, a arte tem um papel político. Ao inserir esse tipo de narrativas em um contexto de senso comum, a fim de construir indivíduos capazes de desenvolver pensamentos mais críticos, pode vir a ser relevante. As narrativas implícitas e explícitas são técnicas que podem ser estudadas e conceituadas, a fim de pensarmos na formação de leitores mais autônomos e com maior capacidade de interpretação, assim como na formação de escritores cada vez mais preparados para utilizarem essas técnicas em suas produções literárias.

\section{Referências}

ASSIS, Machado de. Um Homem Célebre. In: nead.unama.com.br. Cantiga dos Esponsais. Rio de Janeiro: Garnier, 1884. . O Machete. In: Obra completa. Rio de Janeiro: Nova Aguilar, 1994. V. II. . Virginius. In: Obra completa. Rio de Janeiro: Nova Aguilar, 1994. V. II. 
AZEVEDO, Elciene. O Direito dos Escravos: Lutas Jurídicas e Abolicionismo na Província de São Paulo. Campinas: Editora da Unicamp, 2010.

BOURDIEU. Pierre. A Distinção - Crítica Social do Julgamento. Porto Alegre: Zouk, 2020.

ECO, Umberto. Interpretação e Superinterpretação. Trad. Monica Stahel. São Paulo: Martins Fontes, 2005.

- Os limites da interpretação. Trad. Pérola de Carvalho. São Paulo, Perspectiva, 1992.

. Seis passeios pelos bosques da ficção. Trad. Hildegard Feist. São Paulo: Companhia das Letras, 1994.

. Obra aberta: forma e indeterminação nas poéticas contemporâneas. Trad.

Giovanni Cutolo. 2. ed. São Paulo: Perspectiva, 1971.

GARDNER, J. A arte da ficção. Trad. Raul de Sá Barbosa. Rio de Janeiro: Civilização Brasileira, 1997.

JAUSS, Hans Robert. A literatura e o leitor. Rio de Janeiro: Paz e Terra, 1979.

MCKEE, R. Diálogo - a arte da ação verbal na página, no palco e na tela. Trad. Chico Marés. Rio de Janeiro: Arte e Letra, 2018.

MOURA, Clóvis. Dicionário da Escravidão Negra no Brasil. São Paulo: EDUSP, 2004.

SOUZA E LIMA. Músicos negros no brasil colonial: trajetórias individuais e ascensão social (segunda metade do século XVIII e início do XIX). Vernáculo, 2007.

TRINDADE, Rejane. O Direito dos Escravos. Trilhas da História. Três Lagoas, v. 2, n. 4 jan - jun 2013. p. 219-224. 